\title{
Наша основная задача - интеграция науки, образования и бизнеса
}

Рассказывает Ирина Алексеевна Янкелевич, директор Научно-образовательного центра молекулярных и клеточных технологий ФГБОУ ВО СПХФУ Минздрава России

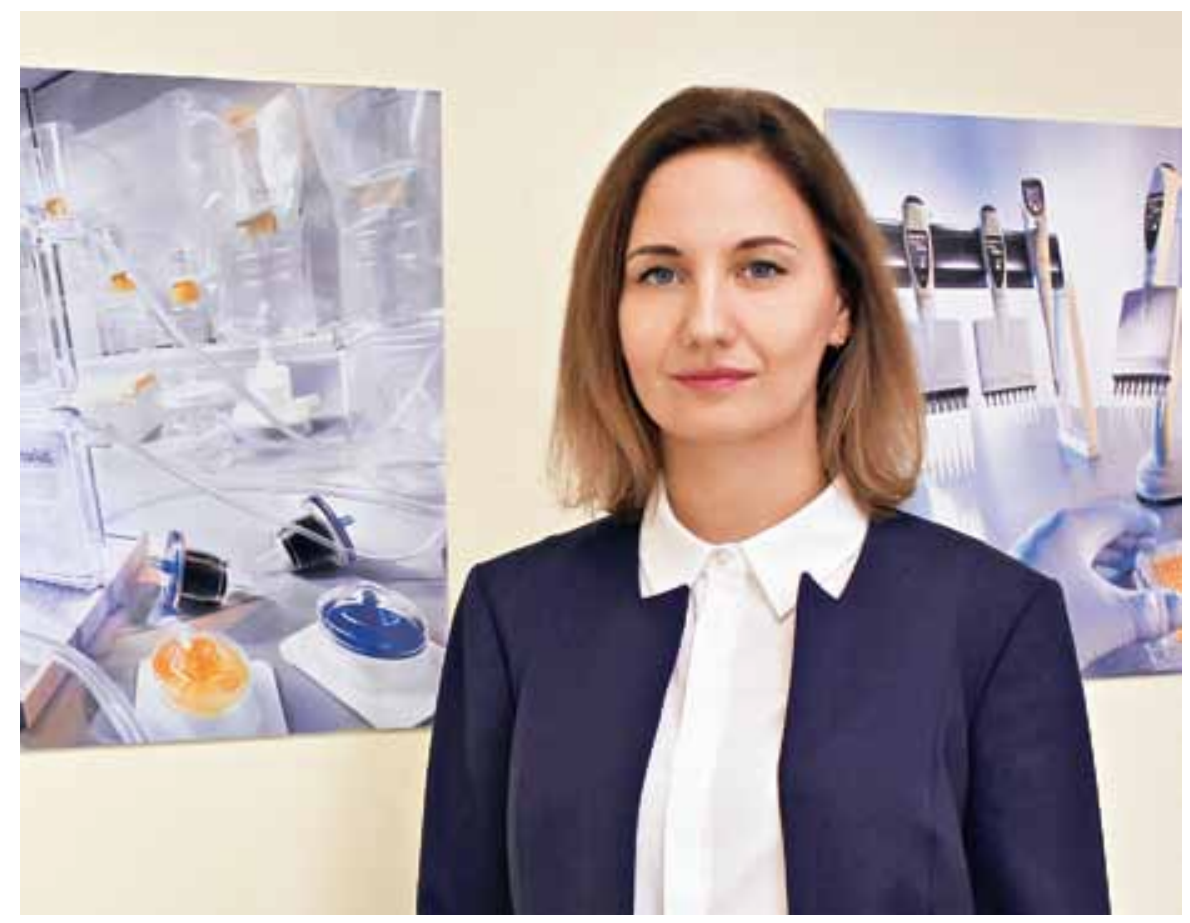

29 января 2019 года на базе Санкт-Петербургского государственного химико-фармацевтического университета (СПХФУ) состоялось открытие современного научно-образовательного центра молекулярных и клеточных технологий (НОЦ МКТ), оснащенного передовым оборудованием международного уровня. Биотехнология - одна из самых динамично развивающихся отраслей и науки, и производства. Исследования и разработки в этой области очень перспективны и востребованы в фармацевтике, медицине, сельском хозяйстве и др. О целях создания центра, оборудовании, направлениях работы, планах сотрудничества с коллегами из других образовательных, научных и коммерческих организаций мы поговорили с директором Научно-образовательного центра молекулярных и клеточных технологий Ириной Алексеевной Янкелевич.

Уважаемая Ирина Алексеевна, расскажите, пожалуйста, об истории возникновения центра. По чьей инициативе он был создан?

Идея формирования практических научно-образовательных центров для нашего Университета не нова. У нас достаточно давно активно работают ориентированные на практический результат специализированные учебно-исследовательские подразделения и регулярно открываются новые. Стремление студентов, аспирантов и научнопедагогического состава СПХФУ идти в ногу со временем и развиваться вместе со сферой наук о жизни подтолкнуло руководство на вполне логичный шаг - создание 


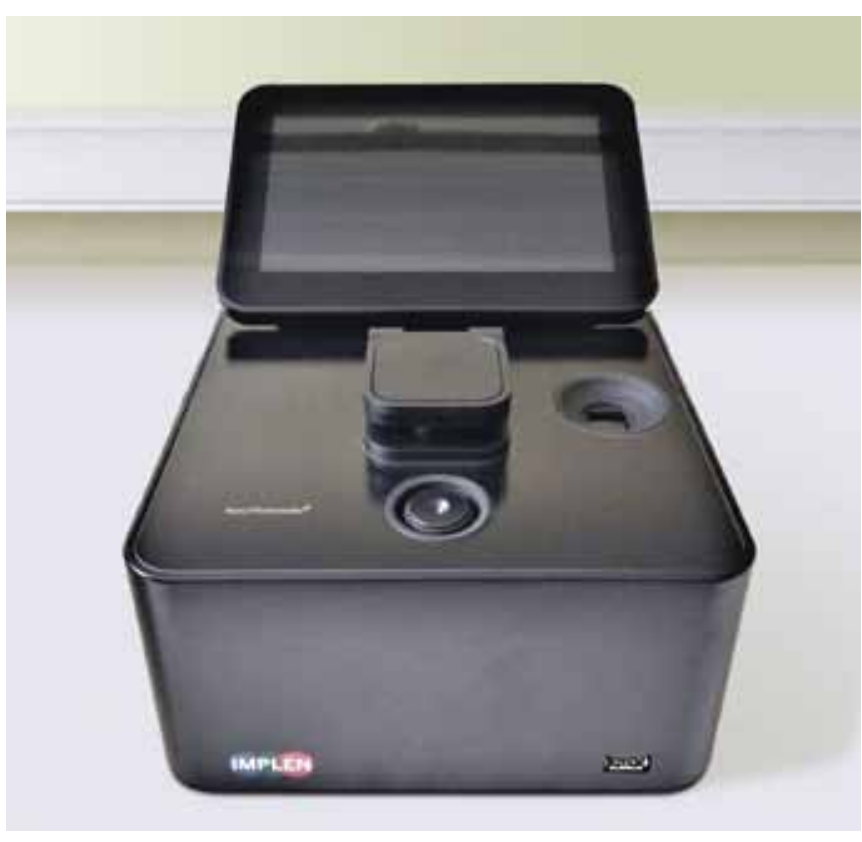

Нанофотометр Implen

многофункционального центра для решения современных задач в области биомедицины и биотехнологии.

Какие задачи стоят перед центром? Какие исследования планируется проводить? В каких проектах он будет задействован?

Среди основных задач можно выделить реализацию концепции интеграции науки, образования и бизнеса. Кроме того, одно из важнейших направлений работы научнообразовательного центра - актуализация образовательных программ Университета для бакалавриата, магистратуры, аспирантуры, курсов дополнительного профессионального образования. Также мы надеемся, что внедрение новых методологий центра повысит научный потенциал нашего Университета.

В наших планах - работа в тесном партнерстве с отечественными и зарубежными научными и образовательными организациями, ведение открытого диалога с представителями отрасли, учет их запросов и включение в научные проекты, ориентированные на потребности производства.

В чем заключается образовательная миссия центра? В каких формах будет проходить работа со школьниками, студентами, слушателями ФПК?

Мы работаем в интенсивно развивающейся отрасли. Поэтому образовательная миссия центра состоит в том, чтобы идти в ногу с современной индустрией и прививать учащимся передовые и актуальные знания и навыки, которые позволят им в будущем стать востребованными специалистами. Учитывая объем информации, находящейся сегодня в открытом доступе, наша задача - не только доступно преподнести обучающимся знания, но и научить их грамотно пользоваться информацией, а также осуществлять ее поиск.

\section{Mы планируем работать в тесном партнерстве с отечественными и зарубежными научными и образовательнымu организациями}

Какая работа для центра приоритетна: научно-исследовательская, учебно-образовательная или коммерческая?

На мой взгляд, все виды деятельности должны быть связаны и нельзя отдавать приоритет какой-либо из них. Необходимо обучать студентов на конкретных практических задачах, привлекать к научной работе, ориентировать исследовательские проекты не только на получение новых фундаментальных знаний, что, безусловно, очень важно, но и внедрять разработки на практике. Поэтому важно не выделять что-то одно, а пытаться извлечь максимальную пользу для каждого из этих направлений путем их взаимодействия.

\section{Расскажите о материально-технической базе центра.}

Материально-техническая база центра позволяет вести научную деятельность в области молекулярной биологии,

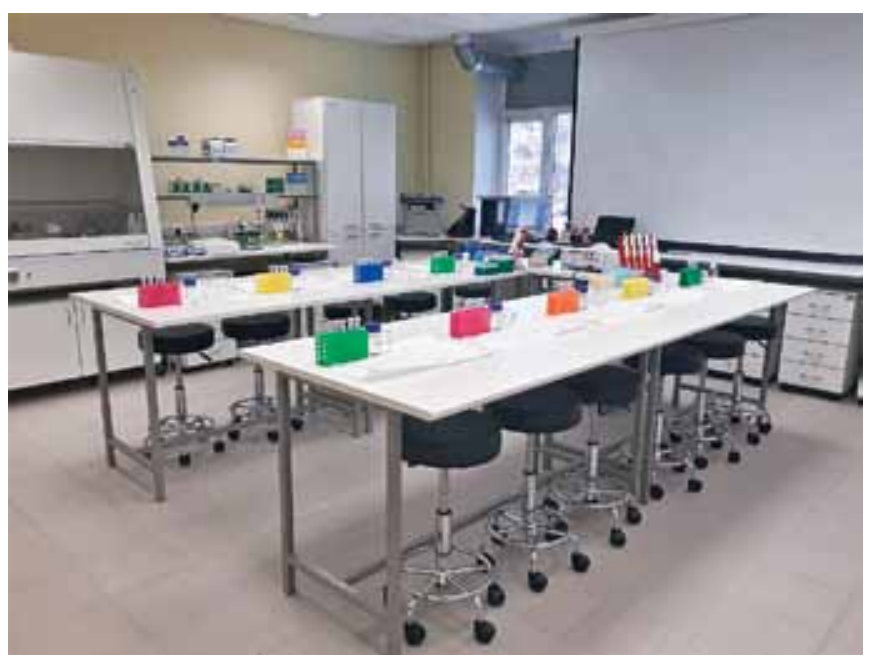

Учебная паборатория Научно-образовательного центра МКТ 
используя ключевые методы анализа биополимеров В лаборатории центра проводятся качественный и количественный анализ белков и нуклеиновых кислот, для чего применяется современный комплекс приборов для постановки одно- и двумерного электрофорезов, а также наноспектрофотометр Implen. Исследование по определению уровня экспрессии генов, а также генотипированию

\section{Среди основных задач}

\section{можно выделить}

\section{реализацию концепции}

\section{интеграции науки, образования и бизнеса}

проводят с использованием планшетного амплификатора CFX 96 производства компании Bio-Rad, одного из наиболее популярных приборов в международной практике. В центре предусмотрены боксы для манипуляций с прокариотическими и эукариотическими продуцентами, оборудованные всем необходимым для работы в аспетических условиях и поддержания оптимального микроклимата для культивирования. Счетчик клеток и инвертированный флуоресцентный микроскоп позволяют проводить подсчет клеток и визуализировать морфологически важные клеточные структуры. Парк оборудования научно-образовательного центра собран для решения целого ряда фундаментальных

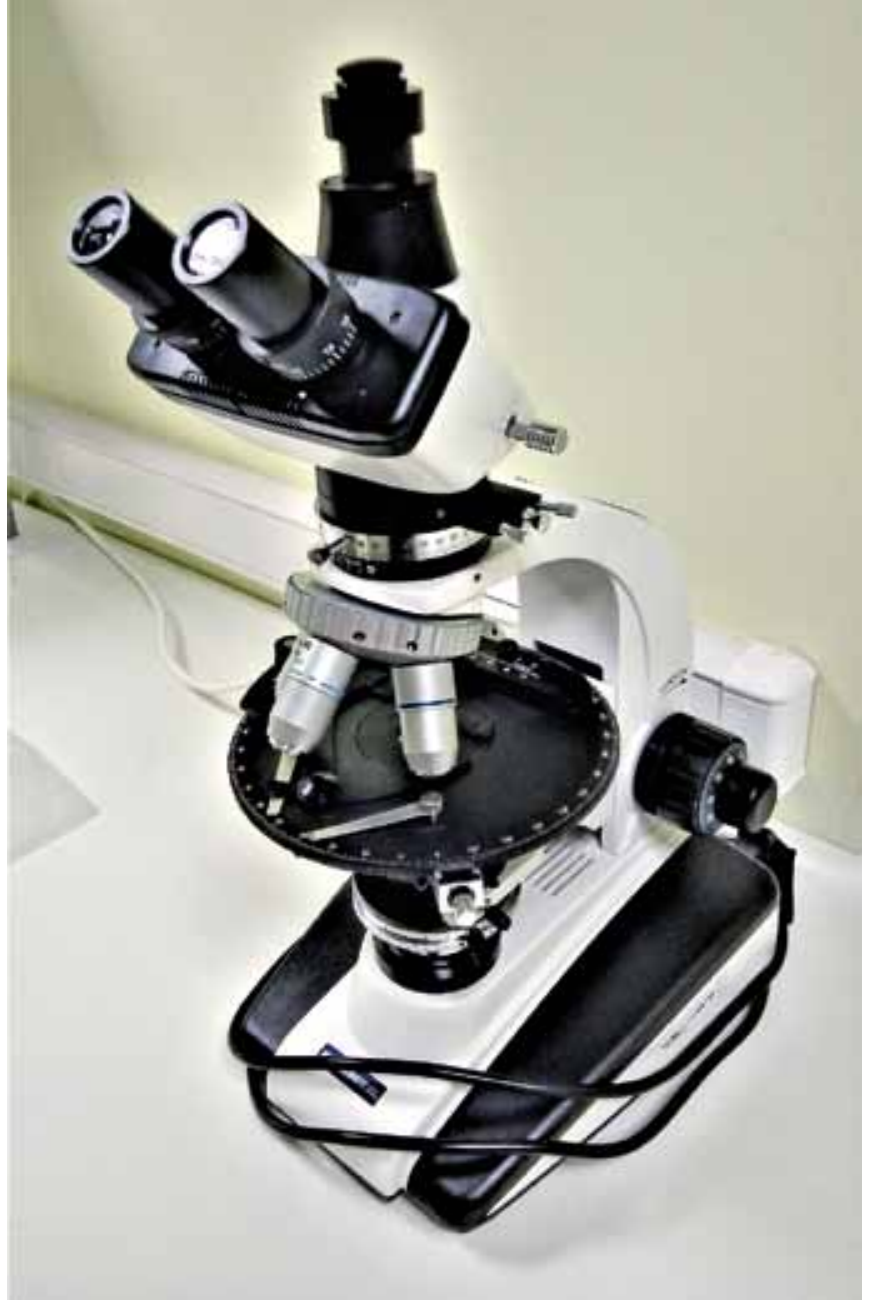

Поляризационный микроскоп "Биомед»

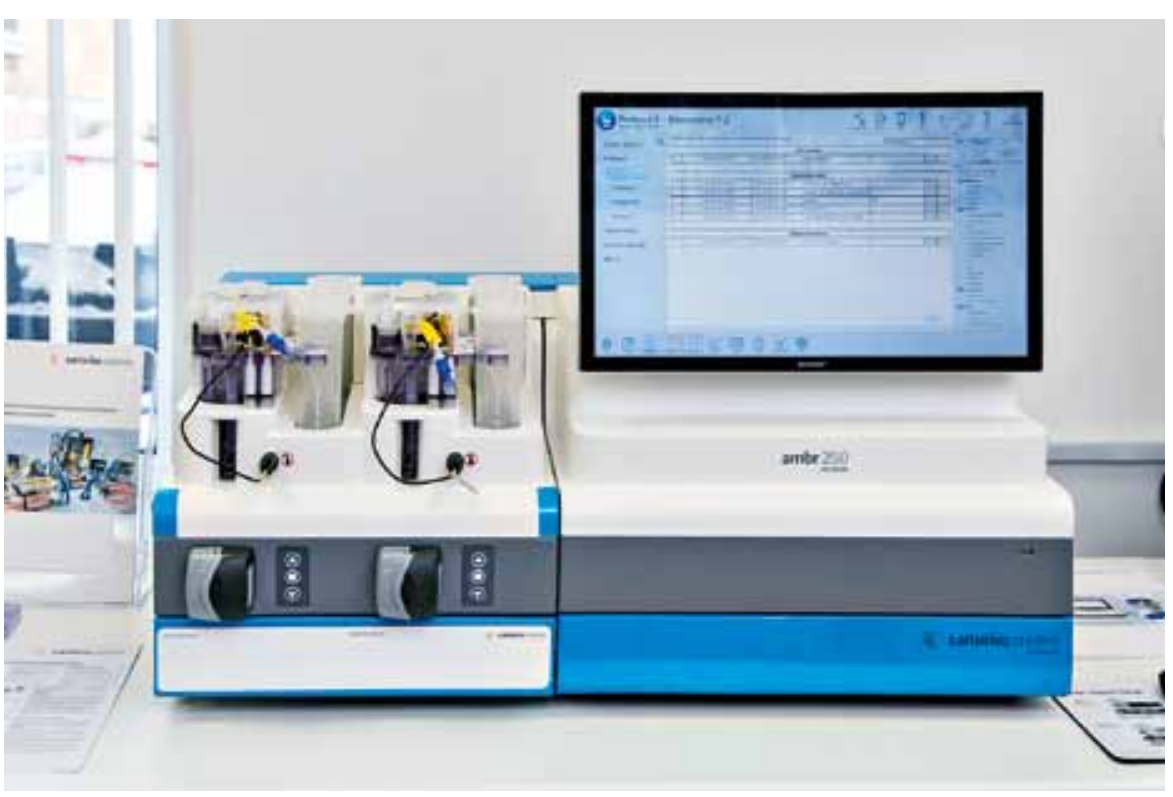

Автоматизированный биореактор ambr 250 modular и прикладных задач биомедицины и биотехнологии.

Расскажите об оборудовании центра. Какие компании его предоставили?

Часть оборудования закуплена на средства, выделенные Министерством здравоохранения на формирование приборного парка Университета. Также стоит отметить, что СПХФУ состоит в партнерских отношениях с международным производителем фармацевтического и лабораторнопромышленного оборудования концерном Sartorius. В рамках этого сотрудничества в центре открыта практическая лаборатория Sartorius, в которой представлено передовое биотехнологическое оборудование, 


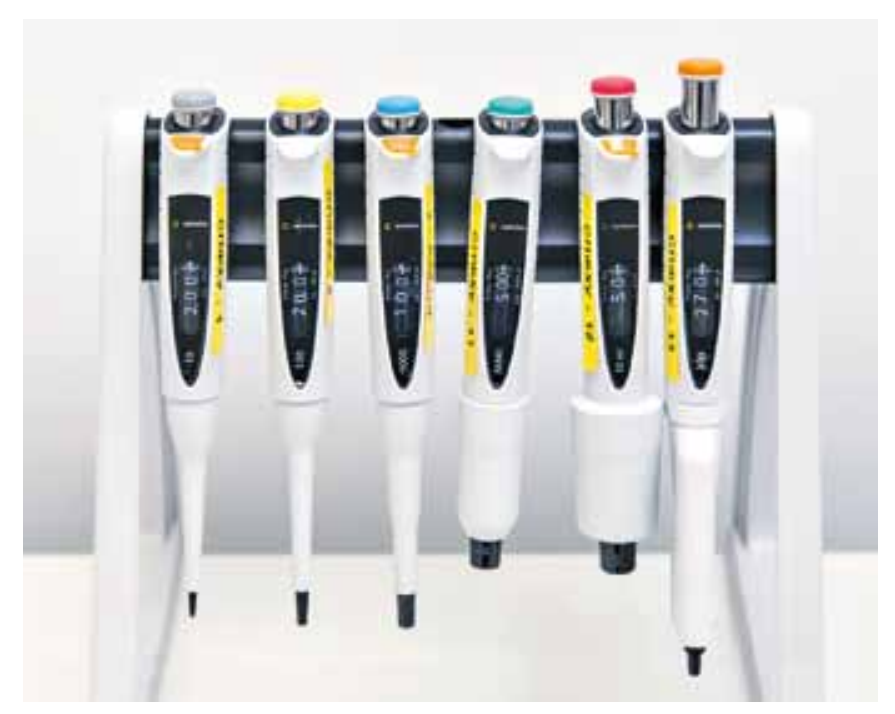

Набор дозаторов Proline Plus

используемое на различных стадиях биотехнологического процесса: система тангенциальной фильтрации Sartoflow Smart, ферментер BIOSTAT A, макет производства сред Lonza, высокопроизводительный автоматизированный биореактор - ambr 250 modular. Оснащение лаборатории подходит как для научно-исследовательской работы, так и для контроля качества получаемых продуктов: механические дозаторы серий Proline Plus и Tacta, электронные дозаторы Picus и Picus NxT, система очистки воды arium comfort І. Отмечу также весоизмерительное оборудование Sartorius, которое можно применять и на производстве и для контроля качества фармацевтической лаборатории. Особого внимания заслуживают модульные лабораторные весы серии Cubis, новый анализатор влажности МА160 и гиревая продукция российского предприятия "Сартогосм".

Кроме того, в оснащении общелабораторным и специальным оборудованием для анализа белковых соединений центру помогла одна из ведущих отечественных биотехнологических компаний - «Биокад". специфических темах и обладающих опытом использования соответствующих методик. На данный момент наш центр занимается развитием сотрудничества с научными центрами и университетами Финляндии, США и Канады.

\section{Как будет строиться взаимодействие с партнерами из учебных, научных и коммерческих организаций?}

Работа в коллаборации - это в первую очередь возможность реализации сложных научных проектов. На сегодняшний день, почти любой научный проект требует участия специалистов из разных областей, формирования междисциплинарных команд от различных организаций. Взаимодействие приводит к плодотворным результатам, когда каждая из сторон привносит свои профессиональные компетенции, а материальнотехническая база расширяется за счет площадок каждого из

\section{Необходимо обучать студентов на конкретных практических задачах}

партнеров. Безусловно, очень полезно привлекать специалистов других учреждений и к образовательной деятельности, например, к чтению отдельных узкопрофильных лекций или спецкурсов. Мы открыты для такого сотрудничества.

Приведу пример плодотворной совместной работы: наш центр, как представитель старейшей российской фармацевтической школы, успешно сочетающей в себе исторические традиции и современные подходы в науке и образовании, и немецкий биотехнологический концерн с мировым именем Sartorius объединили усилия для реализации государственной стратегии развития фармацевтической и медицинской

\section{Планируется ли совместная работа с коллегами из российских и зару- бежных научных организаций?}

Да, конечно. Наука - это область, в которой невозможно эффективно работать без международных взаимодействий. Для достижения действительно значимых результатов в той или иной области науки необходимо быть не только в курсе результатов изысканий коллег всего мира, но также формировать коллективы высокопрофессиональных специалистов, компетентных в достаточно узких

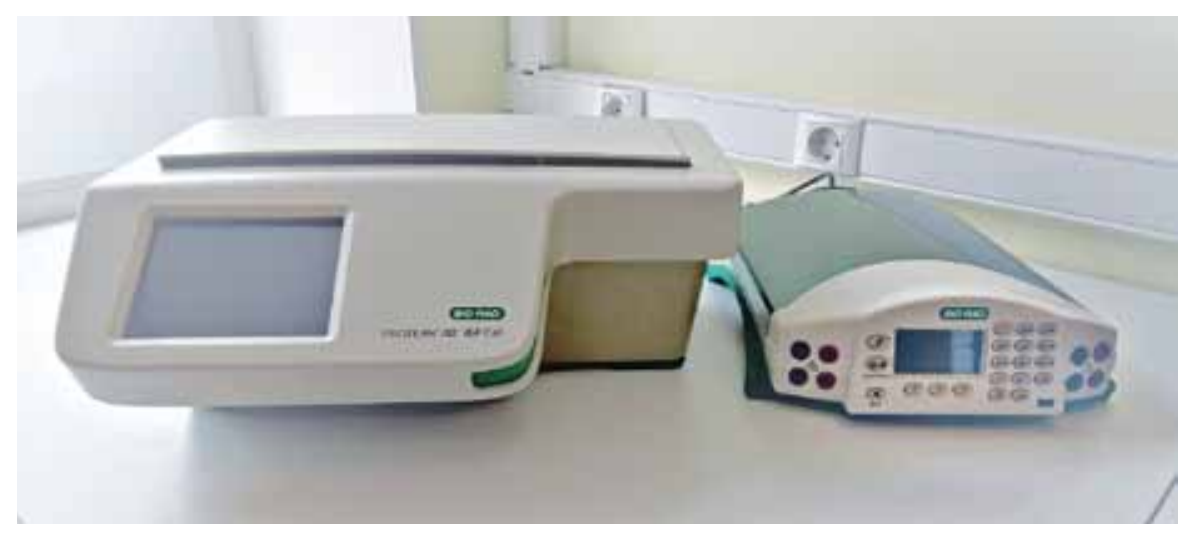

Cистема для изоэлектрофокусирования Bio-Rad 
промышленности Российской Федерации на период до 2030 года и дальнейшую перспективу.

\section{Работа в колиаборации - это в первую очередь} возможность реализации

\section{сложных научных}

\section{проектов}

\section{Расскажите, пожалуйста, о персонале центра.}

Коллектив нашего центра достаточно молодой. В составе штата - аспиранты и молодые ученые разного профиля. Ввиду большого интереса к работе научно-образовательного центра со стороны студентов, мы надеемся, что в обозримом будущем наша команда пополнится талантливыми и целеустремленными молодыми учеными и преподавателями.

\section{Каковы ваши ближайшие и перспективные планы?}

Процесс формирования нового подразделения, ведущего свою деятельность в научной и образовательной областях не тривиальная и трудоемкая задача. Введение в рабочий режим оборудования и отработка методик, формирование и методическое сопровождение новых образовательных курсов, запуск научных проектов и решение инфраструктурных и организационно-административных вопросов - все это на начальном этапе требует значительного времени и усилий от коллектива центра. Поэтому ближайшие наши задачи - это в первую очередь выход центра на режим стабильной и надежной работы в основополагающих процессах. При этом мы стараемся думать на перспективу и уже сейчас закладываем основу для будущего развития - ведем переговоры о новых совместных проектах с коллегами, планируем траектории развития для уже действующих, проводим обучающие семинары для студентов научного студенческого общества, а также разрабатываем новые образовательные программы.

\section{Спасибо за интересный рассказ.}

С И. А. Янкелевич беседовапи В. В. Родченкова и О. А. Лаврентьева

\section{ПЛЕНКА ДЛЯ МАСКИРОВКИ ОТ ИНФРАКРАСНЫХ КАМЕР}

Скрыть инфракрасное (тепловое) излучение от термочувствительных камер может быть полезно для военных и исследовательских задач. Сложность заключается в том, чтобы замаскировать разницу в температурах предмета и окружающей среды. Предыдущие устройства для решения этой проблемы были дороги, неудобны в использовании, работали от электропитания, плохо отводили тепло. Китайские ученые разработали недорогой и простой в производстве способ сделать нагревающиеся предметы невидимыми для инфракрасных камер.

Сначала ученые изготовили пленку аэрогеля из волокон материала Kevlar фирмы DuPont. Волокна растворили в диметилсульфоксиде, нанесли тонкий слой на поверхность, погрузили в деионизированную воду для формирования гидрогеля и высушили при температуре $-50^{\circ} \mathrm{C}$. Полученная пленка имеет высокую пористость и прекрасно изолирует тепло. Затем в структуру пленки ввели полиэтиленгликоль и покрыли защитным гидрофобным слоем. Когда полиэтиленгликоль плавится, он поглощает тепло, а когда затвердевает - испускает. Теплоемкость подобного композитного материала
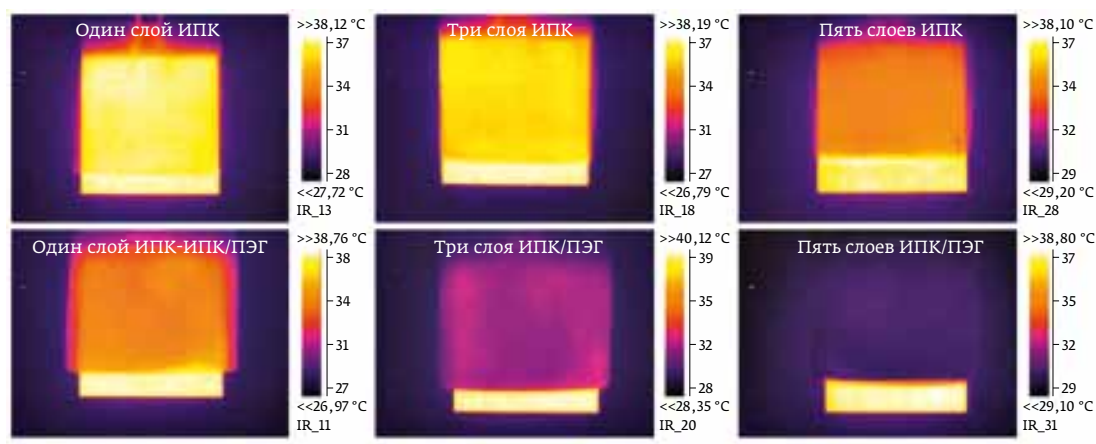

иПК - изолирующая пленка из кевлара

ИПК/ПэГ - композитная пленка из кевлара с добавлением полиэтиленгликоля

можно варьировать, он хорошо сохраняет и проводит тепло. На солнечном свете композитная пленка поглощала солнечный свет, незначительно нагреваясь, и маскировала покрытый ею объект. В темноте она медленно испускала тепло, мимикрируя под температуру окружающей среды. В другой серии экспериментов ученые имитировали условия ночного инфракрасного наблюдения, когда теплый объект выделяется на фоне относительно холодного окружения. Образец покрывали двумя видами пленки: обычной (изолирующей) и композитной (поглощающей тепло). Пяти слоев двойной пленки было достаточно, чтобы полностью скрыть предмет от инфракрасных камер.

Разработанную технологию можно использовать в фундаментальных исследованиях, современной электронике и для военных нужд.

ACS Nano, 2019. DOI: 10.1021/acsnano.8b08913 


\section{Превосходная чувствительность. Исключительная концентрация.}

\section{Система 6500+ QTRAP ${ }^{\circledR}$ с технологией IonDrive ${ }^{\mathrm{TM}}$}

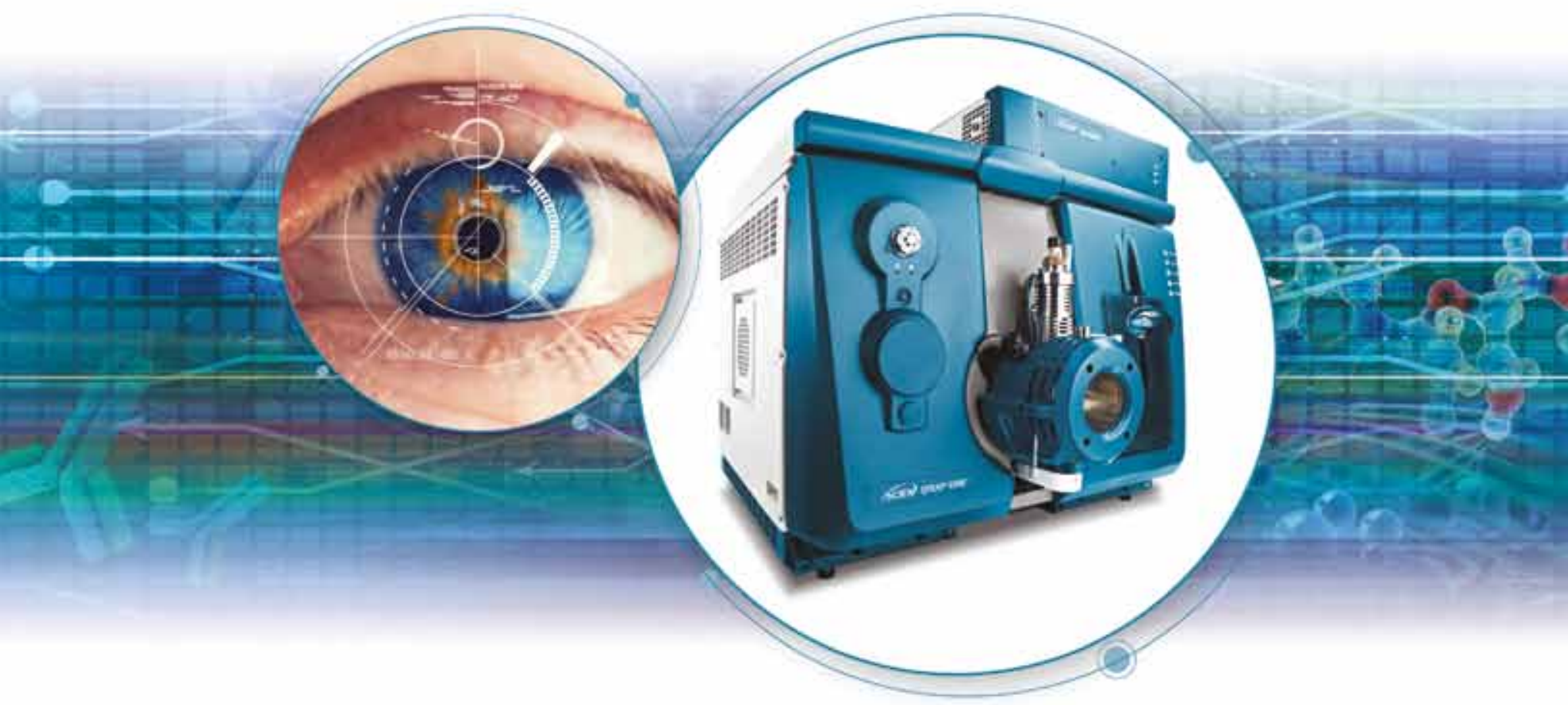

\section{Увидеть, что было скрыто. До этого момента.}

\section{Cистема QTRAPß 6500+ с многокомпонентной технологией IonDrive ${ }^{\text {Tu }}$}

- Самые быстрые и самые чувствительные системы Triple Quadrupole и QTRAP® компании SCIEX

- Улучшенный сигнал-шум в широком диапазоне хроматографического потока и анализируемых соединений

- 6 порядков линейного динамического диапазона

- QTRAP позволяет использовать режим MRMЗ для улучшенной селективности анализируемых соединений Дополнительное усиление селективности для сложных анализов с помощью устройства дифференциальной ионной мобильности SelexION(B)+. Позволяет преодолеть матричный эффект и улучшить качество, обеспечивая надежную количественную производительность.

Система SCIEX QTRAP@ 6500+. Достойный преемник в линейке масс-спектрометрических систем лидера отрасли.

Раскройте полный потенциал чувствительности и селективности на sciex.com

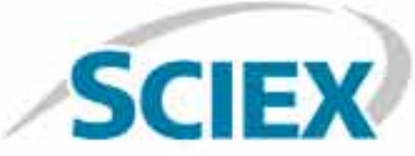

Answers for Science. Knowledge for Life."

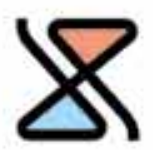

X HM
Дистрибьютор компании SCIEX в России: ООО «Химэксперт», 125009, Москва Страстной бульвар, 4, стр 1, офис 101 Ten,/Фakc: +7 4956292869 E-mail: info@khimexpert.ru www.khimexpert.ru 